\title{
A PAZ PEDE ARTE: OS DIÁLOGOS DE PAZ E SEUS AGENTES ${ }^{1}$
}

\author{
PEACE ASKS FOR ART: \\ PEACE TALKS AND THEIR AGENTS
}

\begin{abstract}
Resumo: Este artigo explora uma agenda de pesquisa teórico-aplicada no âmbito das ciências da linguagem. Como parte da pesquisa, apresentaremos nossa análise de um diálogo, disponibilizado pelo projeto The Palestine Papers, entre negociadores do Estado de Israel e da Organização para a Libertação da Palestina. Abordaremos, assim, um objeto teórico (agência dialógica) e um objeto empírico (diálogos de paz israelo-palestinos). E, a partir do arsenal teórico proposto, dos problemas levantados na análise e de uma proposta de pacificação tomada como base, defenderemos um cenário alternativo de mediação, cujo núcleo é o uso de novos agentes e novas linguagens.
\end{abstract}

Palavras-chave: agência; mediação; negociação; diálogos de paz; conflito israelo-palestino.

\author{
Stéphane Dias ${ }^{2}$
}

\begin{abstract}
This article explores a theoretical-applied research agenda in the language sciences. As part of the research, we will present the analysis of a dialogue, which was made available by The Palestine Papers Project, between negotiators of the State of Israel and of the Palestine Liberation Organization. Thus, we will approach a theoretical object (dialogical agency), and an empirical object (IsraeliPalestinian peace talks). And, from the theoretical arsenal proposed, from the problems raised in the analysis, and from a proposal of pacification taken as a basis, we will defend an alternative scenario of mediation, whose core is the use of new agents and new languages.
\end{abstract}

Key-words: agency; mediation; negotiation; peace talks; Israeli-Palestinian conflict.

As coisas que achei fácil fazer, eles acharam mais fácil não fazê-las.

Jim Rohn

\section{Introdução}

Neste texto, iremos discutir os conceitos de agência e racionalidade comunicativas aplicados ao cenário diplomático-político de mediação de conflitos. Na exposição, consideraremos um cenário de negociação de paz, a partir da análise da estrutura dialógica em questão e de seus agentes.

É fácil compreendermos, por exemplo, que quando uma promessa é feita há expectativas de que quem fez a promessa pode cumpri-la, e parece igualmente natural criarmos expectativas de que a promessa seja de fato cumprida e haja uma reação de

\footnotetext{
${ }^{1}$ Pesquisa realizada na Pontifícia Universidade Católica do Rio Grande do Sul (2012-2016) e na Reuters University (2014-2015). Bolsista de Doutorado - GD, CNPq. Programa CAPES/Fulbright - Estágio de Doutorado nos EUA - Edital no 54/2013.

${ }^{2}$ Doutora em Letras - Linguística. Desenvolve pesquisa interdisciplinar sobre linguagem e diálogo, com foco em agência e racionalidade. Professora substituta no Instituto Federal Farroupilha Campus Santo Augusto e embaixadora Playing for change. ORCID ID: https://orcid.org/0000-0003-3460-2096. Link para o Currículo Lattes: http://lattes.cnpq.br/0444290032159177.Contato: stephanerdias@gmail.com
} 
cobrança se não for. Essas expectativas podem ser explicadas dentro de um quadro de racionalidade comunicativa (GRICE, 1989; SEARLE, 2001), e a elas recorremos para tomarmos decisões eagirmos socialmente. No entanto, nosso comportamento comunicativo insere-se em um cenário prático mais amplo, dentro do qual atuamos em certas funções que geram relações como compromissos, obrigações, deveres e autorizações.

Nesse contexto de análise, nosso objeto de estudo compreende os seguintes componentes: uma tipologia de agentes (indivíduos, membros de grupos e grupos/ representantes) e as ações linguístico-comunicativas desses agentes, tendo em vista metas, razões e comprometimentos.

Iniciaremos, assim, por questões técnicas envolvendo os objetos de análise; depois, passaremos à apresentação e ao tratamento do objeto empírico e, posteriormente, à exposição do núcleo de uma proposta de intervenção no contexto de negociação mediada. Por fim, teceremos conclusões e considerações sobre o estudo que originou este material.

\section{Do tratamento dos objetos teórico e empírico}

Nossa pesquisa busca descrever e explicar atos comunicativos de agentes individuais e coletivos, considerando as metas, razões e comprometimentos existentes. Objetiva-se, assim, contribuir com debates dentro dos estudos do significado, bem como com aplicações para áreas afins, como direito, relações internacionais e relações públicas internacionais.

Nesse sentido, o foco da pesquisa está voltado para o entendimento do uso social de uma estrutura comunicativa da espécie ${ }^{3}$ e para a atuação individual e coletiva de agentes sociais ${ }^{4}$. Particularmente, a pesquisa se insere nos estudos do diálogo de tradição pragmática ${ }^{5}$.

É no contexto desse debate mais amplo que é assumida a hipótese abdutiva de que há uma estrutura de contato dialógico parcialmente invariável entre culturas. Para ilustrar essa hipótese, utilizamos o diálogo de negociação, mais especificamente o de negociação de paz. Entendemos que este projeto mostra-se pertinente não somente para a área dos estudos da linguagem, já que aborda questões de interesse teórico interdisciplinar, mas também traz considerações de interesse prático mais geral à sociedade em que vivemos. 0 objeto ilustrativo da pesquisa compreende transcrições de um diálogo ocorrido em 2005 entre negociadores de Israel e da Organização para a Libertação da Palestina (OLP) .

\footnotetext{
${ }^{3}$ Ver Grice (1989), Hymes (1972), Lepore e Stone (2015), Levinson (2000), Mercier e Sperber (2011, 2017), Pinker (1994), Sperber e Wilson $(1986,1995)$, Tomasello $(2003,2008)$, Weigand $(2009,2010)$, Wilson (2005).

${ }^{4}$ Ver Cohen (1992), Gilbert (1987, 2000), List e Pettit (2011), Schmitt (1994), Searle (1995, 2010), Tomasello e Rakoczy (2003), entre outros.

${ }^{5}$ Ver Costa (2012), Grice (1989), Macagno e Bigi (2013), Weigand $(2009,2010)$. Ver também Sperber e Wilson $(1986,1995)$ e Walton (2007).

${ }^{6}$ A Organização para a Libertação da Palestina (OLP) foi fundada em 1964 como a representação oficial do povo palestino, enquanto um organismo nacional, comportando, assim, um sem-número de organizações de resistência e independência. Até 1994, representava a única instituição reconhecida internacionalmente como legítima. Naquela data, a Autoridade Nacional Palestina (ANP ou AP) foi fundada pela OLP como órgão interino de autogoverno de cinco anos, representando oficialmente o Estado Palestino, resultado dos
} 
Esse material, analisado em nossa tese, serve para um duplo propósito: ilustrar o aporte teórico e representar um contexto sobre o qual teceremos considerações no âmbito das negociações internacionais.

Essas considerações nos levam a defender uma proposta de uso de um tipo específico de diálogo, o diálogo expressivo, isto é, entre artistas, agentes que destacadamente utilizam linguagens de modo expressivo, e seu público. Defenderemos esse tipo de diálogo como ferramenta no processo de mediação ou negociação mediada ${ }^{7}$. Passaremos, assim, a questões centrais de nosso objeto teórico.

\section{O objeto teórico: da agência dialógica}

Iniciaremos refletindo sobre duas funções do contato dialógico, quais sejam: 1) a otimização de estados cognitivos (por exemplo, formar crenças verdadeiras; criar e manter um conjunto de crenças coerente e não contraditório; revisar crenças inconsistentes e revisar grau de crença ou justificação); e 2) a maximização de metas práticas (por exemplo, fechar acordos, manter laços afetivos, barganhar, convencer e persuadir).

Notemos que tal separação é metodológica, já que as noções de meta doxástica (relacionada às crenças) e meta prática (relacionada às ações) se inter-relacionam. Mercier e Sperber (2017), por exemplo, sustentam que a faculdade da razão tem como função principal a produção de convencimento e justificação em nossas interações sociais. É igualmente importante observarmos que condições de sociabilidade e afetividade mobilizam metas dos dois tipos, quando ações e emoções são respostas do organismo à interpretação de estados do mundo.

A noção aristotélica de racionalidade teorética, voltada ao aprimoramento do ambiente conceptual dos agentes, e a noção de racionalidade prática, voltada às ações desses agentes, estão internamente relacionadas, no sentido de que representações acuradas sobre o ambiente e sobre os indivíduos (possibilidades de ação, meios, comprometimentos etc.) são relevantes para tomadas de decisão justificadas, e estas para a ação eficaz, que maximizaria as metas do agente.

A comunicação, nesse contexto de análise, serviria para uma regulação de estados representacionais com conteúdo proposicional (como suposições e crenças) e estados orgânicos mais básicos (como emoções, que não apresentam conteúdo proposicional, não sendo passíveis de serem verdadeiras ou falsas ${ }^{8}$ ). Tais conteúdos estão representados no nível da consciência, que, por sua vez, relaciona-se a uma outra instância obtida via diálogo:

acordos de Oslo. A OLP continua a ser a única representação internacional oficial, mas, na prática, muitos tomam essas entidades de forma intercambiável (PALESTINE LIBERATION ORGANIZATION, 2001).

${ }^{7}$ Agradeço a Dima Mohammed por me questionar sobre a relação do projeto com os processos de "mediação" e "negociação". Os processos de mediação fazem parte do processo de negociação mediada que caracteriza o caso Israel-Palestina, e o nosso projeto contempla as diferentes funções que os mediadores podem assumir no processo de negociação.

${ }^{8}$ Podemos aqui fazer um paralelo com a teoria da arte para fins de exposição. Por exemplo, podemos pensar em arte conceitual (representações sobre estados-de-coisas reconhecíveis) e representações não conceituais, isto é, abstratas (em que não há representações individuadas, ou cujo conteúdo representacional é elaborado a partir das sensações que ele gera). 
a regulação do agente com seu meio social, visando objetivos práticos e a sociabilidade (DIAS, 2014). Tais relações estariam na base da ação comunicativa, individual ou coletiva (DIAS, 2016) ${ }^{9}$. E as respectivas habilidades representacionais e comportamentais seriam instanciadas dialogicamente de forma a regular estados internos e as relações do agente com seu meio social.

Parece, assim, que generalizações sobre a ação comunicativa dependem de generalizações sobre a ação de modo geral. Entretanto, ações linguístico-comunicativas possuem particularidades relevantes. Consideremos: quando alguém faz uma pergunta a um interlocutor, ou o elogia, ou o cumprimenta, em uma escala de proatividade comunicativa, esperamos que este reaja comunicativamente de maneira adequada à ação inicial. Essas são situações cuja estrutura é similar à de quando alguém intencionalmente lhe toca a bola esperando que você a chute ${ }^{10}$. No entanto, no caso da linguagem, a ação depende de vários níveis de conteúdo, cuja noção de adequação se aplicará a cada um. É importante ponderarmos que, no caso do chute, nossa reação também dependerá, em parte, de nossa percepção de onde estamos, da idade de quem nos toca a bola, de nossa relação com essa pessoa etc. Nesse sentido, desconsiderando-se similaridades mais gerais às ações, no caso da linguagem natural temos um conjunto potencialmente maior de representações envolvidas e, consequentemente, de possibilidades de reação.

Logo, a agência comunicativa diz respeito à atuação de agentes para atingir metas práticas. Segue-se que a noção de agência é aqui explorada em termos performativos (DIAS; MÜLLER, 2017), contemplando uma tipologia de agentes (indivíduos, membros de grupos e grupos/instituições/representantes), atos (desde pedidos a posições oficiais de grupos) e relações deônticas (como direitos, obrigações, deveres, intitulações e comprometimentos). Atos de fala ${ }^{11}$, como analisaremos, estão na base da ação de agentes sociais.

Como justificativa da relevância desse quadro teórico-metodológico, defenderemos que a noção de agência é central para teorias da comunicação e do significado. Havendo alternância de agência, há também de significados veiculados. Como exemplificado em Dias (2016, p. 107), tomemos dois atos declarativos: 1) John Smith, um cidadão norte-americano, declara na televisão: "eu amo Barack Obama"; 2) Malia Ann Obama, uma cidadã norteamericana, declara na televisão: "eu amo Barack Obama”. Conforme argumentado (Ibid.), no primeiro enunciado o nome próprio "Barack Obama" veicula como informação central o ex-presidente dos Estados Unidos e, no segundo enunciado, "Barack Obama” veicula como informação central meu pai. Ou seja, nos dois enunciados os falantes fazem referência à mesma entidade no mundo atual, mas o sentido do nome próprio não é o mesmo, apontando para diferentes propriedades do referente no mundo real (FREGE, 1892). No primeiro caso, o falante faria referência ao ex-presidente (papel social, agente) e, no segundo caso, ao pai (papel (bio)social, agente). 0 mesmo enunciado, assim, carregaria conteúdos de sentidos distintos ao ser expresso por agentes distintos; e nós, falantes e agentes sociais competentes, sabemos identificar esses conteúdos nos seus contextos de uso.

\footnotetext{
${ }^{9}$ É nessa perspectiva que assumimos uma ideia de cognição social. Ver, por exemplo, Powell e Spelke (2013).

${ }^{10}$ Sobre a estrutura de ação e reação em diálogos, ver Weigand $(2009,2010)$.

${ }^{11}$ Ver Austin (1962) e Searle $(1975,2010)$.
} 
Dentro desse cenário, adicionemos o fato de que agentes, individualmente ou coletivamente, entram em conflito. Por disputas de interesse ou entendimento, no campo dos recursos, estatuto social ou das ideias, há desacordos dialogicamente expressos. E tais desacordos parecem expressos em uma estrutura de interação dialógica comum, sendo aqui observadas as especificidades do contexto de negociação de paz.

Consequentemente, na tentativa de ilustrar esse quadro, teceremos considerações sobre o raciocínio dialógico dos agentes envolvidos e, com base nestas, apontaremos alguns problemas relacionados ao tipo interação. Por fim, defenderemos uma proposta alternativa ao quadro problemático evidenciado.

Como tal cenário será apresentado através de uma análise do que se convencionou chamar de diálogos de paz, precisamos contextualizá-los. Seguem, então, considerações sobre esse tipo de interação no seu contexto sócio-histórico e político mais amplo.

\section{O objeto empírico e um cenário de paz: considerações}

Primeiramente, teceremos algumas considerações sobre o objeto empírico ilustrativo desta pesquisa, qual seja, um diálogo de negociação registrado por escrito em ata oficial, tendo em vista: 1) o conflito que demanda as negociações consideradas nas análises; 2) o tipo de diálogo em questão; e, por fim, 3) os agentes em negociação.

Os diálogos de paz oficialmente realizados entre o Estado de Israel e a OLP são marcados por tensão e barganha, já que muitas das decisões incidem sobre questões estratégicas para ambos, como suprimentos e libertação de pessoas. A descrição de elementos da estrutura dos diálogos, sobretudo de suas propriedades linguísticocomunicativas, mostra-se, assim, com relevância prática imediata. Ademais, tais diálogos são objetos empíricos apropriados para ilustrar integralmente o arcabouço conceitual de nossa pesquisa.

0 projeto The Palestine Papers ${ }^{12}$ nos oportunizou o contato com dados oficiais caros à ilustração de pontos centrais de nossa argumentação. A divulgação por parte da Al Jazeera de mais de 1.600 documentos confidenciais, de e-mails a reuniões privadas, datados de 1999 a 2010, facilitou a escolha do objeto empírico. Após lermos vários documentos, optamos por um diálogo representativo de acordos entre as partes ${ }^{13}$; no ano de 2005, em um momento de transição de governo, negociadores se reuniram para tratar de questões como acessos e prisioneiros. É também relevante mencionarmos que a língua das negociações é o inglês. Por motivos de espaço, aqui nos deteremos em três trechos do diálogo. Contextualizemos, então, os atos dialógicos a serem apresentados, tendo em vista o conflito em questão.

\footnotetext{
${ }^{12}$ Por favor, visite: <https://bit.ly/UIZZBD>. Acesso em: 26 nov. 2017.

${ }^{13}$ Para ter uma visão geral dos contextos envolvidos, por favor, leia o texto de nossa pesquisa publicado em inglês (sobretudo DIAS, 2016, p. 137-146) bem como as referências ali mencionadas.
} 


\section{O conflito}

Eisenberg e Caplan (2010) mencionam nomenclaturas como "paz árabe-israelense", "conflito Árabe-Israel", "conflito israelo-palestino", "processo de paz israelo-palestino" ou “árabe-israelense". Gelvin (2014), como Caplan (2009), chama o evento principal de "o conflito Israel-Palestina" (a tendência, na literatura recente sobre o conflito, parece ser colocar o nome "Israel" e o adjetivo "israelense" em primeiro lugar). Há dois pontos de tensão interligados por essas denominações. Um, mais amplo, e outro, mais específico. 0 mais amplo diz respeito a tensões entre representantes árabes e sionistas, cujas primeiras reuniões de negociação expressiva sobre território datam de 1913-1914 (EISENBERG; CAPLAN, 2010, p. xx).

Igualmente, a história de diplomacia entre as partes é tão extensa quanto seus insucessos. Tendo em vista que a área sob disputa era habitada, no início do século passado, por árabes-muçulmanos e que guerras envolvendo outros países árabes foram travadas nos anos subsequentes, o conflito maior leva o nome da comunidade. Com a independência de Israel em 1948 e a expulsão de 700.000 famílias árabes do território (Ibid., p. 15), aquela extensão geográfica tornar-se-ia território palestino-israelense, e o conflito pela terra estaria configurado.

Após 1948, as reivindicações passaram a envolver: a) determinação sobre fronteiras; b) o estatuto de Jerusalém; c) acesso a recursos hídricos; e d) retorno ou reassentamento de centenas de milhares de refugiados palestinos (Ibid.). É nesse quadro complexo que podemos interpretar decisões militares, de Estado, de coalizões, de partidos políticos e de organizações internacionais e religiosas como posições de grupos e de seus subgrupos institucionais.

Assim, os nomes "Israel" e "Palestinos" fazem referência, a partir de 1948, respectivamente, a um Estado oficialmente judeu, com representação internacional (o Estado de Israel ${ }^{14}$ ), e a uma comunidade de maioria árabe, em um território que, na época, saía do domínio britânico. A partir de diversas guerras territoriais e expulsões em massa, estariam em disputa o reconhecimento e a soberania de dois Estados. Guerras armadas e políticas só se somariam nos anos subsequentes.

Durante o século XX, inúmeros ataques e represálias apontaram para a necessidade de negociações reais e efetivas entre as partes. A intervenção de terceiros no jogo diplomático, em especial das instituições internacionais, vem deixando o cenário de mediação mais complexo e burocrático ao longo das últimas décadas.

Enquanto negociações de paz, esses encontros reúnem representantes que obtêm e dão andamento a acordos. Consequentemente, considerando os objetivos e os estatutos

\footnotetext{
14 De um lado, o Estado de Israel é declarado em 1948. De outro, a Declaração de Independência autoproclamou o Estado da Palestina em 15 de novembro de 1988. Mas somente em 29 de novembro de 2012 a Assembleia Geral das Nações Unidas (ONU) aprovou o "reconhecimento de fato do Estado soberano da Palestina" (já a condição de Israel como membro das Nações Unidas começa em 11 de maio de 1949). Por 138 votos, a Assembleia Geral da ONU aprovou o estatuto da Palestina enquanto "Estado Observador Não Membro" (UNITED NATIONS, 2003). No entanto, o reconhecimento do Estado ainda não é unânime no cenário internacional.
} 
sociais das partes em contato, podemos abstrair um tipo de estrutura de interação. Passemos a essa estrutura.

\section{Negociação de paz}

0 tipo de diálogo em questão, como descrito por Walton e Krabbe (1995), classificase como diálogo de negociação, isto é, uma interação de barganha. A finalidade desse tipo de diálogo é a obtenção de um acordo, baseado em interesse próprio, sobre a alocação ou divisão de recursos, humanos ou materiais. No fim, o acordo de paz é um ato de fala, do tipo que Searle (1975) denomina de "comissivo" (isto é, que compromete o agente a realizar o que oferece/aceita ser realizado ${ }^{15}$ ), que pode gerar um ato declarativo (ou seja, as autoridades competentes, num acordo final de negociação, podem criar um estado de paz ao dizer que ele será instaurado).

Assim, compreendemos que as negociações não estão centradas em compromissos com a verdade das proposições usadas pelos agentes (WALTON, 1989, p. 8). Centram-se, sim, nas posições dos grupos, na obtenção dos melhores acordos, enquanto planos de ação. Nesse jogo expresso sob forma de diálogo, requer-se que as partes aceitem ou disputem interpretações e posições e que usem dos mecanismos adequados para defendê-las ou atacá-las ${ }^{16}$.

As iniciativas diplomáticas de negociações de paz contemporâneas falharam em diversos aspectos. Eisenberg e Caplan (Op. cit., p. 2) apontam tensões nas negociações árabe-israelenses envolvendo, centralmente, os seguintes elementos: experiências prévias de negociações conjuntas, uma variedade de propósitos e motivações, questões de timing, o estatuto dos parceiros de negociação, o envolvimento de terceiros, os termos dos acordos e fatores psicológicos. Desse modo, o alicerce da retórica política de negociação, que soma mais de 100 anos de tratativas, merece ser reconsiderado na sua complexidade.

Nos últimos 15 anos (2002-2017), as negociações de paz buscaram obter atos como cessar-fogo, pausa de retaliações mútuas, libertação de prisioneiros e retorno de direitos e bens. 0 próprio termo "paz", diga-se, é disputado nesse cenário político. Vale ressaltar ainda que o diálogo, por meio dessas negociações, permite: 1) ação conjunta (a partir do contato entre agentes para decisões e atos); 2) compreensão entre as partes (a partir do contato com a expressão de posições e das razões na base destas); e, finalmente, 3) um estado de paz (a partir da prática desses acordos). No entanto, tal meio se mostrou ineficiente ou insuficiente.

Para entendermos as falhas centrais do processo, precisamos entender as negociações e os agentes em diálogo. As negociações são, em grande parte, encontros presenciais entre representantes oficiais, mas não entre chefes de Estados, e sim entre

\footnotetext{
${ }^{15}$ Ver Tiersma (1986).

16 Como exemplos desses mecanismos, consideremos posições e declarações de representantes do Departamento de Estado norte-americano sobre o fechamento do escritório da OLP em Washington, tendo em vista uma lei aprovada pelo congresso que prevê que "a OLP não pode operar um escritório de Washington se instar o Tribunal Penal Internacional a processar israelenses por supostos crimes contra palestinos" (KEINON, 2017, tradução minha).
} 
profissionais dedicados à diplomacia dessas instituições (Israel e OLP). Tais encontros consistem em negociação em contexto formal, isto é, com protocolos e metas coletivas pré-estabelecidas, em lugares distantes do conflito direto e por meio de um idioma que não é a língua materna dos envolvidos no conflito.

Na base dessas decisões comunicadas, que são basicamente posições de grupos, temos razões ou justificativas ${ }^{17}$ de seus membros e representantes. Nesse jogo, assume-se a verdade de algo (proposição assumida) para tomada de decisão, que, uma vez tomada, se torna a posição do coletivo que ela representa. A suposição de que os agentes agirão conforme suas posições e comprometimentos assumidos faz avançar as tratativas; do contrário, há ruptura de diálogo ${ }^{18}$. Respondendo por essas posições, temos: grupos, subgrupos e seus representantes.

\section{Agentes}

As posições dos grupos são sustentadas por razões. Assim, precisamos entender quem as assume e quais são as suas motivações. De forma mais geral, partimos de uma tricotomia de tipos básicos de agência, quais sejam: indivíduos, membros de grupos e grupos/instituições (e seus representantes).

Ao longo da vida, pessoas tomam decisões e realizam ações visando maximizar objetivos da sua agência individual, em última instância sobrevivência e satisfação de desejos. Nesse nível de agência, todos os seres humanos têm metas em comum, e conseguimos identificá-las como metas do organismo, tais como buscar nutrientes, abrigo e proteção. É nesse sentido que assumimos metas individuais diferentemente daquelas que são coletivas ou institucionais.

Ao mesmo tempo, os seres humanos, como criaturas sociais, tornam-se membros de grupos nas diversas formas de vida em sociedade. Um membro institucional é um agente que tem metas e compromissos coletivos, uma vez que sua agência existe em função dessa estrutura coletiva. Desse modo, as pessoas assumem compromissos e têm objetivos compartilhados em seus grupos.

As instituições são, por sua vez, agentes sociais individuais e coletivos, já que podem existir independentemente de qualquer membro específico, sendo reguladas por metas institucionalmente assumidas, que são criadas por pessoas em certas funções. Tais metas ou objetivos estão relacionados com as demandas internas e externas dos grupos: internamente, os membros regulam sua ação para atingir os fins impostos à instituição, quer seja juridicamente, politicamente, de comum acordo ou de modo impositivo.

A ideia básica é que, no âmbito da agência social, os agentes institucionais agem por meio de posições, que representam as decisões internamente tomadas por membros, pois

\footnotetext{
${ }^{17}$ Ver, por exemplo: RASGON, Adam. Palestinians reject Trump team's reasons for threatening closure of DC PLO office. The Jerusalem Post, Jerusalem, 29 nov. 2017. Disponível em: <https://bit.ly/2JU3PG2>. Acesso em: 27 nov. 2017.

${ }^{18}$ Ver, por exemplo: FARRELL, Henry. Thanks to Trump, Germany says it can't rely on the United States. What does that mean? The Washington Post, Washington, DC, 28 maio 2017. Disponível em: <https://wapo. st/2JEGQiV>. Acesso em: 27 nov. 2017.
} 
elas têm, acima de tudo, valor prático para o grupo ou instituição. Como consequência, tais posições são assumidas por todos os membros, enquanto membros, quando agindo em nome da instituição. 0 histórico de posições oficiais reflete, assim, a agência da instituição, que é independente da de seus membros. Nesse sentido, há certas posições da Igreja Católica, dos EUA, da Autoridade Palestina (AP) ou da Organização das Nações Unidas $(\mathrm{ONU})$ às quais membros atuais e novos devem se adequar quando agindo enquanto membros dos grupos. E esse ponto é extremamente importante para entendermos restrições e compromissos dos agentes em jogo nas negociações.

Quando pensamos nessas instituições como agentes, nos perguntamos: em que sentido posso tomar a ONU como um "agente" tal qual seu secretário-geral? Como pode um agente institucional sem mente ter metas, deveres e compromissos próprios? A resposta para a primeira questão é que, tal como o secretário-geral, a própria instituição tem obrigações, direitos, deveres, compromissos e responsabilidade legal por tais relações deônticas contraídas e por ações institucionais.

O filósofo John Searle (2010) assume que agentes humanos entram em relações deônticas como portadores de direitos, obrigações e normas, e que as instituições humanas seriam uma extensão da deontologia promovida pela nossa capacidade representacional, que nos permite atribuir funções a certas entidades (SEARLE, 2010, p. 4).

Essa interpretação, no entanto, não parece captar o espectro central da agência de tais instituições, embora contribua para a discussão da natureza do tipo de representação envolvida. $\mathrm{O}$ fato é que criamos entidades passíveis de contrair compromissos e deveres e de responder por atos e omissões, já que a União Europeia ou a ONU podem ser cobradas por atos realizados em seus nomes e a elas atribuídos. Ao mesmo tempo, vamos ao encontro da ideia de Searle de que esse tipo de fenômeno é uma extensão da deontologia humana ao assumirmos que as metas, deveres e compromissos institucionais são criados e atribuídos às instituições por indivíduos em certas funções, tanto na constituição quanto na organização dessas entidades (DIAS, 2016, p. 99). Uma vez criada, no entanto, a deontologia passa a envolver as instituições enquanto portadoras desses poderes e deveres, e esse aspecto é central nas relações institucionais e interinstitucionais.

Passemos, então, para o caso ilustrativo que envolve agentes institucionais específicos. A complexidade do caso Israel-Palestina nos permite explorar os aspectos acima mencionados.

\section{Da ilustração}

Dado o cenário descrito, consideremos que o quadro teórico será ilustrado por um diálogo de negociação entre membros de instituições, os quais, em tese, tinham como objetivo dialógico fechar acordos institucionais. Esse objetivo, a princípio, estaria a serviço de um objetivo prático maior: fechar um acordo final de paz. Iremos identificar as instituições envolvidas e seus representantes logo abaixo.

Conforme já mencionado, os dados advêm de atas de negociação entre os dois lados no conflito israelo-palestino, constituindo tomadas de decisão até pouco tempo secretas 
da diplomacia internacional. A data do documento é 14 de fevereiro de 2005. Conforme expresso em Dias (2016, p. 143-144), a negociação sob análise é, provavelmente, a primeira reunião de negociação realizada após a cúpula de Sharm el-Sheikh, que ocorreu em 8 de fevereiro de 2005. Essa cúpula foi a primeira reunião "de negociação direta" entre o presidente Abbas e o primeiro-ministro Sharon, na presença de Mubarak, presidente do Egito, e Abdullah II, rei da Jordânia. As aspas são aqui utilizadas tendo em vista que ocorreram encontros antes da cúpula entre representantes das instituições para acertar justamente os termos e as condições das negociações, resultando em acordos antes da cúpula, como afirmam os representantes na reunião de 3 de fevereiro de 2005:

Hassan Abu Libdeh (HAL), Palestina: "We want the summit to be successful but we need to agree all parameters earlier." [...]

Mohamad Dahlan (MD), Palestina: "We cannot go to summit before we agree this." Dov Wiesglass (DW), Israel: "We want to release these agreements today."

Hassan Abu Libdeh (HAL), Palestina: "[T]here will be no negations in Sharm El Sheikh all has to be agreed before summit."19 (THE PALESTINE PAPERS, 2005, p. 2-3)

Dado que essa reunião aconteceu no Crown Plaza Hotel em Tel Aviv, em 3 de fevereiro de 2005 , das 16 h às 19 h30, assumimos que a reunião de sequência, ocorrida no dia 14, deu-se em semelhantes circunstâncias. 0 título da minuta diz: "Reunião preparatória para a reunião do presidente Abbas com o primeiro-ministro Sharon, 14 de fevereiro de 2005, notas da reunião" ${ }^{2020}$. E, como visto, as cúpulas não são encontros decisórios, uma vez que as reais negociações se dão entre representantes dos chefes dos mais altos comandos, a portas fechadas, antes dos eventos midiáticos.

Consideremos, desse modo, os seguintes agentes do diálogo de negociação:

\section{Palestina: Grupo}

Dr. Saeb Erekat $(S E)$ : Chefe da delegação e alto representante do Grupo ${ }_{1}$ e negociadorchefe da Autoridade Palestina (AP).

Mohamad Dahlan (MD): Membro do Fatah ${ }^{21}$, ex-líder do Fatah em Gaza.

Subgrupo $_{1}$ do Grupo $:(O L P)$ Saeb Erekat está na função de principal negociador da OLP. Subgrupo $_{1}$ do Subgrupo do Grupo $_{1}$ : Departamento de Negociações $(D A N)^{22}$. Saeb Erekat está na função de chefe da NSU.

\footnotetext{
19 Tradução aproximada:

Hassan Abu Libdeh (HAL), Palestina: Queremos que a cúpula seja bem-sucedida, mas precisamos acordar todos os parâmetros antes.

Mohamad Dahlan (MD), Palestina: Não podemos ir à cúpula antes de acordarmos isso.

Dov Wiesglass (DW), Israel: Queremos liberar esses acordos hoje.

Hassan Abu Libdeh (HAL), Palestina: Não haverá negações em Sharm El Sheikh tudo tem que ser acordado antes da cúpula.

${ }^{20}$ No original: "Preparatory meeting for President Abbas meeting with Prime Minister Sharon February 14, 2005 Meeting Notes". Nas atas dos dois encontros (de 3 e 14 de fevereiro) constam os mesmos negociadores, com exceção de dr. Hassan Abu Libdeh, do lado palestino, e de Asaf Shariv, do lado israelense. Nossa hipótese é de que esses seriam os membros responsáveis pelas atas do dia 14 .

${ }^{21}$ Fatah: partido político nacional que representa a maioria da OLP.

22 O Departamento de Assuntos de Negociação é o ramo técnico da OLP encarregado das negociações, fornecendo assessoria jurídica para o lado palestino (PALESTINE LIBERATION ORGANIZATION, 2001).
} 
artigo

Subgrupo $_{2}$ do Subgrupo do Grupo $_{1}$ : (Fatah) Saeb Erekat é reconhecido como um membro e representante do Fatah.

Israel: Grupo

Dov Wiesglass $(D W)$ : Chefe da delegação e alto representante do Grupo ${ }_{2}$. É também reconhecido como assessor de Ariel Sharon.

Amos Gilad $(A G)$ : Major-general israelense.

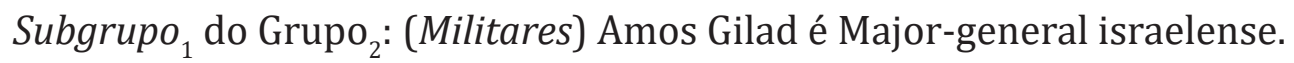

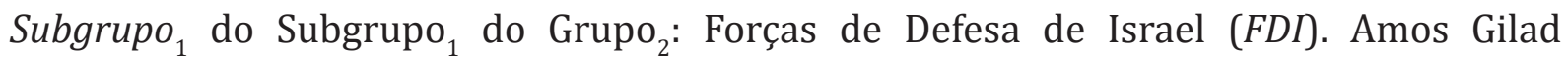
representando o comando dos Assuntos Políticos e Militares do Ministério da Defesa.

Após ter uma dimensão dos diferentes grupos, enquanto instituições e representantes envolvidos, considere o diálogo ${ }^{23}$ entre os agentes acima mencionados: Trecho $1^{24}$

SE: I was informed today of the proceedings of the commanders level meeting for handover of Jericho. There is a major problem since the Army is rejecting the agreements we reached in this forum and refuses to lift the checkpoints.

The Army is rejecting the removal of the DCO checkpoint on Route 90 and the cement roadblock on the Northern exit of Jericho on Route 90 . They agreed to remove Aim Dyok checkpoint but they however want to erect a new checkpoint 900 meters away which will change nothing.

$A G$ : There is a meeting today at 10:00 PM between Mofaz and the Chief of Staff and the Jordan valley commander. I will participate in this meeting and we will discuss this. It is my understanding of the agreements reached in this forum that the checkpoints and road blocks will be lifted. I do not know what happened but we will try to sort it out tonight.

$D W$ : This is my understating too. But now it is at the Minister's level and he knows and is informed what we agreed here. Hopefully it will be sorted out.

Note: there was not commitment to remove all checkpoints but the issue was kept for review at Israeli internal cycles. (THE PALESTINE PAPERS, 2005, s/p., grifos meus).

Tendo em vista expectativas sobre encaminhamentos e agentes, os negociadores interpretam cada passo do diálogo. E os negociadores agem em direção ao cumprimento do que Macagno e Walton (2014, p. 206) chamam de uma "meta de conversação coletiva", o que, neste caso, seria obtenção de acordos. Cada encontro desses interlocutores objetiva metas específicas, mas há vários níveis de ação por meio do diálogo (ao responder ou encaminhar algo, o agente pode estar igualmente reforçando um ponto, mudando a direção das negociações, retardando ações, retirando acordos etc.). Consideremos que "a meta global do diálogo determina a meta local dos movimentos específicos dos interlocutores" (Ibid., p. 206).

\footnotetext{
${ }^{23}$ Optamos por manter os trechos do diálogo na língua original, sem recorrer a traduções livres, pois falaremos sobre este e outros trechos no corpo do trabalho.

${ }^{24}$ Os grifos são aqui utilizados pela atora para destacar atos de fala/agência dialógica coletiva mencionados, e seus agentes.
} 
A cadeia de raciocínios é construída por meio das expectativas e do que é expresso, explícita ou implicitamente, no diálogo. Sabe-se que o que é ali posto já foi deliberado internamente nos grupos. 0 que é apresentado, então, são as posições de cada parte. E as posições são apresentadas por meio de respostas, relatos, atas e devolutivas.

Ademais, não se trata de mera exposição unilateral, mas sim de um jogo em que, com cada movimento, o agente apresenta uma resposta adequada ao movimento do parceiro ou do adversário. E sabe-se que avanços, comprometimentos e acordos devem estar explicitamente expressos nas minutas $^{25}$, já que, nas negociações, cada passo é acordado entre as partes e assim registrado para que valha nas interações subsequentes. Nesse sentido, é importante a leitura dos efeitos obtidos através de cada ato, interpretados a partir das evidências fornecidas na sequência do diálogo.

Conforme descrito em Dias (2016, p. 148-149), os objetivos práticos compartilhados pelos negociadores da Palestina seriam algo como: enquanto negociadores, objetivamos 1) negociar as nossas condições no acordo de paz, 2) resolver algumas violações de compromissos conjuntos, 3) acomodar as objeções da outra parte e, finalmente, 4) concordar em futuras ações conjuntas, sujeitas à aprovação final por parte de Abbas e Sharon na próxima reunião.

Nesse cenário comunicativo, podemos verificar uma estrutura dialógica em que cada fala é motivada por objetivos internos ao diálogo, bem como por objetivos partilhados por grupos e subgrupos. Consideremos, assim, a seguinte cadeia de atos linguísticos em curso no diálogo em questão:

1) I was informed today of the proceedings of the commanders level meeting for handover of Jericho.

2) There is a major problem since the Army is rejecting the agreements we reached in this forum and refuses to lift the checkpoints.

3) The Army is rejecting the removal of the DCO checkpoint on Route 90 and the cement roadblock on the Northern exit of Jericho on Route 90.

4) They agreed to remove Aim Dyok checkpoint but they however want to erect a new checkpoint 900 meters away which will change nothing.

O negociador que ouve tais atos pode representá-los do seguinte modo: por meio de 1), meu adversário nas negociações está abrindo o diálogo ao mencionar o que está registrado em atas de reunião do comando militar israelense, conteúdo a respeito do qual teria sido informado. Na sequência, por meio de 2) ele declara que há um problema principal em relação ao Exército e justifica a causa do problema, a saber: a rejeição por parte deste dos acordos firmados, sobretudo a recusa de realizar ação específica acordada. Na sequência, por meio de 3), o agente informa explicitamente os fatos específicos que

${ }^{25}$ Para uma visão mais clara desse ponto, ver as minutas da reunião do dia 3 de fevereiro de 2005 (THE PALESTINE PAPERS, 2005). 
configuram a rejeição dos acordos firmados por eles. Por meio de 4), ele continua a exposição de um acordo firmado e do plano do Exército israelense, que estaria contrariando o acordo. Para além disso, através da escolha do termo "eles", torna-se manifesto que os agentes em questão não estão presentes (DIAS, 2016, p. 151).

Assim, o negociador do outro lado da mesa de negociação, e igualmente comprometido em firmar acordos, reage. A melhor hipótese formulada pelo agente é a de que lhe foi requerida uma explicação sobre o desrespeito aos compromissos conjuntos, ou então a garantia de que irão resolver o problema. 0 diálogo segue do seguinte modo:

5) There is a meeting today at 10:00 PM between Mofaz and the Chief of Staff and the Jordan valley commander.

6) I will participate in this meeting and we will discuss this.

7) It is my understanding of the agreements reached in this forum that the checkpoints and road blocks will be lifted.

8) I do not know what happened but we will try to sort it out tonight.

Parece que o agente compreendeu não somente o pedido, implícito, de explicação como também o pedido, igualmente implícito, de ação, postos pela outra parte no diálogo (Ibid., p. 153).

A reação dialógica, assim, mostra-se adequada às expectativas, ao iniciar pelo que pode ser considerado como o movimento oponente mais relevante: o pedido de ação (Ibid.). Uma vez que o agente não visa se comprometer com a afirmação de que $p$ (caracterizando um ato de fala comissivo, ao se comprometer com a realização de um determinado estado de coisas futuro), ele executa um ato com diferente força ilocucionária (Ibid.):

$\mathrm{F}: \mathrm{F}(p)^{26}$

7) It is my understanding of the agreements reached in this forum that (the checkpoints and road blocks will be lifted).

Ou seja, o ponto ilocucionário aqui é do tipo assertivo, pois temos a asserção de algo (de que algo $p$ é o caso ${ }^{27}$ ), a saber: o entendimento do negociador de que os postos de controle e bloqueios de estrada serão levantados ${ }^{28}$. A asserção é proferida por um agente no exercício da função de negociador, e a condição preparatória dessa asserção, isto é, o acesso desse agente à evidência da verdade do conteúdo proferido, é sua exposição aos acordos alcançados no fórum e sua compreensão sobre esses acordos. Por isso, é importante que os negociadores acompanhem todo o processo de negociação. 0 ponto

\footnotetext{
${ }^{26}$ A descrição utiliza terminologia empregada por Searle e Vanderveken (1985), em Foundations of illocutionary logic.

${ }^{27}$ Isto é, $p$ faz referência à proposição, ou conteúdo proposicional, em questão.

${ }^{28} 0$ termo "levantamento" é utilizado em conformidade com traduções realizadas em contexto similar pelo Parlamento Europeu, conforme podemos verificar em: <https://bit.ly/2liKikQ>. Acesso em: 22 maio 2017.
} 
ilocucionário assertivo (em que o falante tem como objetivo falar sobre o que ocorre, ou apresentar um estado de coisas como verdadeiro) foi preferido no lugar do uso do ponto ilocucionário comissivo (em que o falante se compromete com a realização de algo). 0 raciocínio do agente envolve a suposição de que sua posição lhe exige reconhecer que acordos geram comprometimentos.

No entanto, mesmo expressando um entendimento sobre acordos e sobre a realização de algo (o que tem implicações dialógicas precisas quando dito por alguém com autoridade para comandar a execução da ação), a força do ponto ilocucionário é mobilizada de modo a mitigar a pressuposição do comprometimento institucional com a realização da ação futura. Ou seja, há concordância com a posição expressa pelo negociador oponente a respeito dos comprometimentos anteriores, ao mesmo tempo em que se evita gerar um novo comprometimento, forte e explícito, por parte da agência que ele representa (enquanto representante e enquanto grupo).

Desse modo, observamos o cuidado com as escolhas linguísticas que o tipo de diálogo requer, tendo em vista a possível atualização de comprometimentos conjuntos e unilaterais. No contexto do diálogo de negociação de paz em que se encontram, e conforme expresso em nosso trabalho (DIAS, 2016, p. 153), tal passo pode evitar uma confirmação de violação de compromissos conjuntos por parte de $\mathrm{G}_{2}$ (Israel), o que seria um movimento arriscado, já que representaria um avanço para uma das partes e um ato inoportuno para a outra.

0 agente, então, afirma que não sabe o que aconteceu ("I do not know what happened"), mas que tentarão resolver a questão. Esse recurso evidencia a agência coletiva envolvida ${ }^{29}$, ali representada por $\mathrm{AG}$, que age enquanto membro do grupo. 0 agente igualmente mitiga a geração de um comprometimento de resolução da questão por parte do grupo, ao apenas enunciar que irão tentar resolver a questão à noite ("we will try to sort it out tonight") (Ibid., p. 153).

Consequentemente, os agentes que processam essa cadeia de passos linguísticos constroem hipóteses acerca da tática dialógica de negociação do grupo (Ibid., p. 153). A sequência do diálogo é bastante ilustrativa da complexidade desse processo.

Trecho 2

$D W$ : This is my understating too. But now it is at the Minister's level and he knows and is informed what we agreed here. Hopefully it will be sorted out.

Ou seja, um agente membro do mesmo grupo reforça a posição de que não há disputa de entendimento (Ibid., p. 154) e, consequentemente, deixa manifesta a existência do comprometimento por parte de $G_{2}$.

9) This is my understating too.

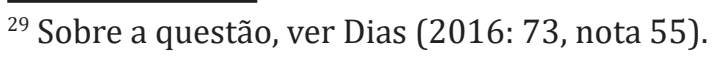


Ademais, a expressão "my understanding" ("meu entendimento") pode ser usada de forma a deixar ambígua a agência em questão: o negociador estaria falando enquanto membro do $G_{2}$ ou, em uma agência mais restrita, enquanto membro da mesa de negociação?

Os atos linguísticos subsequentes são igualmente relevantes para o jogo dialógico:

10) But now it is at the Minister's level and he knows and is informed what we agreed here.

A conjunção "but" ("mas") introduz uma ideia contrastante com o conteúdo anteriormente expresso. Precisamente, ainda que o entendimento do negociador seja compatível com o entendimento do seu oponente na negociação, e ainda que eles tenham firmado comprometimentos conjuntos, o fato de a decisão estar a cargo do ministro ("now it is at the Minister's level") incide sobre o poder decisório do negociador. E o fato de o ministro saber e estar informado do que foi acordado na mesa de negociação ("he knows and is informed [of] what we agreed here") pode representar uma possibilidade de respeito aos acordos e comprometimentos firmados entre os negociadores, mas não o garante.

Ou seja, temos claramente a evidência de restrições de agência afetando o processo de negociação, dada a hierarquia imposta sobre poderes decisórios (Ibid., p. 154).

11) Hopefully it will be sorted out.

"Hopefully" ("com esperança" ou "assim se espera") é outra expressão utilizada de modo a atenuar um compromisso declarado. Tal uso evidencia que os negociadores não estão em posição de afirmar que a questão será resolvida ("it will be sorted out"). Além disso, seu uso não pode ser considerado uma expressão de gentileza, dada a consideração de que esse tipo de ato não é funcional dentro do tipo de interação estabelecida. Mais uma vez, a cadeia de compromissos fica frágil, já que a tomada de decisão final pode, de novo, não considerar compromissos coletivos firmados (Ibid., p. 154) ${ }^{30}$.

Algumas considerações são relevantes aqui. Como podemos notar, há vários agentes envolvidos para o cumprimento da meta final do diálogo, a saber: os acordos. É possível verificar uma alternância de agência, já que falam enquanto representantes e enquanto membros de grupos e subgrupos, bem como enquanto indivíduos (há passagens que ilustram esse caso ao longo do diálogo). Na grande mídia, no entanto, a agência central é das instituições. São esses os agentes em evidência, já que os negociadores não são popularmente conhecidos. Por outro lado, a confiança nas instituições também se revela na dependência da confiança em seus membros, funções essas exercidas por indivíduos. 0 entrecruzamento entre agências faz, assim, parte do jogo dialógico em contexto de

\footnotetext{
${ }^{30}$ Para informações contextuais sobre a questão, ver nota 191 da tese de Dias (2016, p. 154).
} 
negociação. Como consequência, trabalhar com negociação envolve operar agências. Tal operação é ambígua, no entanto; muitas vezes, não fica claro se os compromissos assumidos por um agente institucional serão cumpridos por outro indivíduo na mesma função, ou se quem participou da negociação tomará a decisão final, estando comprometido com os acordos firmados, como vimos. No fim, o compromisso é do agente institucional, não do indivíduo, o que pode facilitar que ocorra rompimento de compromissos.

Diante desse cenário, observemos a seguinte sequência da interação, em que fica clara a alternância de agências ${ }^{31}$ :

Trecho $3^{32}$

SE: Qassam Barghouti? You told us here that he was to be released, we got back to our people and told them and you retracted.

$D W$ : All 500 prisoners, first batch, will be released Monday morning, at 6:00 AM. We already instructed military. You must take care of the media coverage.

SE: What about Barghouti?

$D W$ : Bring his case, as the first case of the prisoners committee. We, the team here, made mistake and we are sorry for it, we told you he is going to be released but he is not.

This should be the first case at the committee. We already talked to Zippi Livni about it. $\mathrm{He}$ is not sentenced or convicted yet.

$S E$ : But that is not what we agreed, you are retracing. Same old tactics that don't help us.

MD: This is personal request, personal embarrassment to me.

$D W:$ We will convey this and consider it.

As agências entrecruzadas no diálogo são as seguintes: indivíduos, membros de grupos/subgrupos e agentes coletivos e seus representantes. É notável, por exemplo, que Mohamad Dahlan fala sobre pedido e constrangimento pessoal (enquanto indivíduo, $I$ ) Dr. Saeb Erekat fala enquanto "nós", tanto no sentido do subgrupo de negociação quanto do grupo que ele representa (Palestina, $G$ ). Dov Wiesglass, por sua vez, fala enquanto membro do subgrupo de negociação de Israel $(M)$.

Como vimos, em geral o nível de comprometimento das partes é muito baixo (ver, por exemplo, DIAS, 2016, p. 167), o que dá suporte à visão de insucesso das negociações. Reforçamos, assim, a visão de que o diálogo parece ser necessário, mas não suficiente para a obtenção de um acordo de paz. Igualmente, reforçamos que o objetivo da interação não é atingir a verdade, sendo esta apenas instrumentalmente necessária. Por fim, é possível reafirmar que a noção de agência apresentada desempenha um papel importante na descrição de metas, intenções e compromissos dos agentes.

\footnotetext{
${ }^{31}$ Sobre esse ponto, ver material apresentado no evento Tardes de Linguística (Universidade de São Paulo), disponível em: <https://bit.ly/2MAGnMx>. Acesso em: 18 jun. 2018.

${ }^{32}$ Os grifos são aqui utilizados pela atora para destacar atos de fala/agência dialógica coletiva mencionados, e seus agentes.

${ }^{33}$ Podemos ilustrar esse ponto com inúmeros trechos de atos dialógicos divulgados pela mídia ao longo das negociações de paz que envolvem agentes institucionais (membros de grupos e representantes). Observemos um exemplo recente na matéria do The Guardian: "Donald Trump tells Abbas 'we will get it done' on Israel-Palestinian peace deal". Disponível em: <https://bit.ly/2liFGev>. Acesso em: 27 nov. 2017.
} 
Considerados alguns problemas centrais do tipo de diálogo em questão e, sobremaneira, da estrutura que se estabelece no caso específico avaliado, passemos para a parte propositiva da pesquisa no campo prático: a proposta alternativa de cenário de negociação mediada.

\section{Da proposta alternativa}

Finalmente, considerando-se os pontos levantados acima, podemos sinalizar como problemas centrais do tipo de formato de negociação de paz em vigor os seguintes aspectos: 1) os negociadores não têm o status adequado, ou seja, não têm os poderes deônticos necessários para realizar um acordo final; 2) as relações de comprometimento são mais fortes internamente aos grupos e subgrupos, sendo mais fracas entre os grupos e seus respectivos membros; 3 ) compromissos são estabelecidos mas não necessariamente cumpridos, sendo que os agentes institucionais ( $G$ e $M$ ) estão comprometidos.

Há, ainda, dois pontos essenciais a considerarmos: primeiro, há níveis de agência relacionados a cada tipo de comprometimento, já que membros estão parcialmente comprometidos, instituições estão nominalmente comprometidas e indivíduos naturais estão, a princípio, descomprometidos com os acordos. Pensemos nos comprometimentos que temos diariamente em nosso trabalho e que, ao mudarmos de emprego, são transferidos para outra pessoa ou anulados, já que estavam vinculados ao cargo. Infelizmente, acordos de paz estão sujeitos às mesmas regulações. Assim, no caso de uma submeta como obter acordo de soltar prisioneiros, supostamente Dov Wiesglass enquanto representante do governo israelense, ou membro do grupo de negociadores israelenses, pode atingi-la, mas não Dov Wiesglass enquanto indivíduo (DIAS, 2016, p. 161, 165, 168) ${ }^{34}$.

Segundo: comprometimentos firmados dependerão de atos e metas dos representantes em nível superior na hierarquia das instituições envolvidas. Negociadores, por exemplo, têm direito, enquanto membros do grupo, de firmar compromissos em nome das instituições, mas não têm poder de decisão final. Tal processo cíclico é apresentado da seguinte forma em Dias (2016, p. 161-162): 1) estabelecem-se acordos internos aos grupos (comprometimentos conjuntos), considerando-se a negociação interna e a hierarquia dos agentes envolvidos. Depois, 2) há negociação entre representantes dos respectivos grupos (eles relatam a primeira parte do processo e estabelecem novos compromissos conjuntos), considerando-se a negociação externa e os poderes de decisão para a ação. Por fim, volta-se aos acordos internos aos grupos (em que relatam o segundo momento e estabelecem novos comprometimentos conjuntos), considerando-se as negociações internas e externas e poderes de tomada de decisão para a ação ${ }^{35}$.

Conforme ilustrado, o cenário padrão de negociação israelo-palestino apresenta baixa taxa de sucesso ${ }^{36}$, sobretudo em função da quebra de comprometimentos conjuntos.

\footnotetext{
${ }^{34}$ Um agradecimento a Fábio Rauen por mencionar esse ponto em sua avaliação da tese da autora.

${ }^{35}$ Ver Dias (2016, p. 162).

36 Tomemos como exemplo a negociação a respeito da greve de fome entre os prisioneiros palestinos (i24News. Disponível em: <https://bit.ly/2JQAEoh>), ou dados sobre a opinião de israelenses acerca
} 
É natural, assim, que nos convençamos de nossa incapacidade de resolvermos conflitos desse tipo. No entanto, há alternativas comunicativas viáveis para a realização de um acordo de paz efetivo.

Conforme exposto em Dias (2013), defendemos que um dialogador especial, envolvido com um tipo de diálogo presente nas mais diversas culturas, deve ser aproveitado para o cenário de negociação: o artista. Este tem as condições de: 1) aproximar as partes; 2) liderar as negociações mantendo a opinião pública atenta aos compromissos firmados; e 3) evitar compromissos com subgrupos não representativos dos interesses das coletividades envolvidas.

Defendemos o uso diplomático-político desses agentes capazes de liderar o tipo mais empático de diálogo existente: o estabelecido por meio da função expressiva da linguagem e encontrado nas diversas artes, esportes e ciências ${ }^{37}$. 0 diálogo expressivo é assimétrico (de poucos agentes para muitos, mas de um modo que traz benefícios a todos), universal (de amplo alcance, pelo uso de linguagens não simbólicas, e com efeitos psicológicos obtidos independentemente de restrições socioculturais) e apelativo aos sentidos (os comunicadores se conectam psicofisicamente através de estímulos persuasivos). Ou seja, propriedades dos comunicadores e propriedades da linguagem por eles manipulada possuem apelo junto aos grupos.

A ideia defendida, assim, é a de que o diálogo expressivo (DIAS, 2013, 2016, p. 180-190) pode constituir-se ferramenta privilegiada para uma aproximação eficaz, a mediação necessária, e para uma negociação com vistas à ação coletiva. Agentes políticos, como vimos, têm uma agência limitada, já que esta é regida por compromissos com subgrupos e desrespeita a mesa de negociações, estando as próprias possibilidades de ação circunscritas às instituições envolvidas. Como decorrência desse tipo de diálogo de barganha e dos "dialogadores" envolvidos, as interações centram-se em interesses unilaterais. Nas negociações de paz, o objetivo dialógico é obter um acordo de paz. Para tanto, os negociadores precisam ser aceitos como representantes do bem comum, não apenas de interesses menores.

Agentes das artes, por sua vez, manipulam e têm a capacidade de fazer emergir estados emocionais que, de outro modo, não têm espaço nas negociações. Tais agentes têm facilidade para estabelecer contato e conexão (BARENBOIM; SAID, 2004), com consequente influência sobre tomadas de decisão. Para além desse poder persuasivo e de encantamento incomuns, eles chamam mais atenção para o próprio diálogo, com efeitos diretos sobre a opinião pública internacional. Como exemplo desse fenômeno, tomemos o movimento Boicote, Desinvestimento e Sanções (BDS) ${ }^{38}$, que defende um boicote ao Estado da "impossibilidade" de um acordo com os palestinos (The Jerusalem Post. Disponível em: <https://bit. ly/2K3OqTu>). Ou, ainda, considere este tipo de campanha de votação Israel vs. Palestina (disponível em: <https://bit.ly/2I1iCK2>). Acesso em: 27 nov. 2017.

${ }^{37}$ No esporte, os jogadores se valem de uma linguagem corporal de modo expressivo. Na ciência, os grandes comunicadores utilizam uma retórica impactante aliada ao impacto do conteúdo de suas proposições.

${ }^{38}$ Agradecemos as valiosas indicações de parecerista da revista a respeito dos seguintes grupos: orquestra West-Eastern Divan, Heartbeat.fm e All for Peace Radio. Trata-se de iniciativas promovendo diálogo não 
de Israel em função das condições impostas aos palestinos. Recentemente, Roger Waters e Thom Yorke, dois músicos proeminentes do cenário internacional, se envolveram em uma discussão pública a respeito da questão, na oportunidade de um show do Radiohead em Israel. Enquanto o primeiro defende o movimento BDS, o segundo se manifesta contrário. A discussão em si voltou a atenção de muitos para o conflito e para os argumentos elencados pelos músicos da defesa de uma ou de outra postura.

É notável o apelo dos artistas, sobretudo os da música e do futebol, e sua capacidade de mobilização das pessoas e de seus grupos. E a explicação para isso parece envolver o fato de que nossa estrutura emocional é mobilizada de uma forma particular pela linguagem artística e por seus comunicadores ${ }^{39}$.

Nesse contexto comunicativo, defendemos uma mudança na estrutura de negociação, oportunizando que um novo tipo de agente mediador e, se necessário, negociador possa operar, dada sua eficiência para a obtenção da meta dialógica final envolvida. Particularmente, tal estrutura pode resultar numa articulação entre agentes que antes se mostrava improvável. Presenciamos uma lacuna de contato com vistas à resolução definitiva, de modo que o cenário seja alterado e projetos alternativos, testados.

A estratégia de intervenção mediadora trazida é justificada por critérios como mobilização de grupos e indivíduos e eficácia na obtenção de tomadas de decisão mais altruístas, incapazes de aparecer em cenários de barganha convencionais, mas possíveis de aparecer em cenários de empatia e sinergia entre as partes.

Enquanto conteúdos proposicionais podem manter as pessoas em desacordo epistêmico ou prático, mobilizações emocionais de ordem estética tendem a aproximar indivíduos psicofisicamente, em função de características das linguagens mobilizadas. Estados emocionais são, muitas vezes, dominantes sobre estados intencionais, além de que o carisma pode ser um elemento decisivo para tomadas de decisão, bem como pode ajudar a despertar a opinião pública para a relevância dos acordos e diálogos.

Nos diálogos expressivos, como consequência, as pessoas compartilham sensações, sentem juntas, para além de pensarem e agirem juntas. E, nos cenários de negociação tal como o ilustrado, precisamos de mais empatia na base das tomadas de decisã $0^{40}$. Precisamos chegar a acordos que visem a benefícios mais amplos, que olhem vários lados do conflito, e não apenas aqueles atrelados a subgrupos e em nome de interesses de minorias.

oficial através da arte, de modo a utilizá-la como veículo para a paz (ver lista completa disponível em: <https://bit.ly/2tdg3jm/>. Acesso em: 18 jun. 2018). É importante mencionarmos que exemplos mais concretos de como se estruturaria essa proposta alternativa de negociações e de como os comunicadores seriam inseridos nos diálogos e em projetos de pacificação serão objetos de exposição de um próximo trabalho.

${ }^{39}$ Sobre aspectos dessa questão, ver Yeung et al. (2014), Lerner et al. (2015) e Jung et al. (2014).

${ }^{40}$ Ver, por exemplo, a mensagem de Ariana Grande diante do atentado em Manchester: ?leu não quero seguir o resto do ano sem ser capaz de dar uma força aos meus fãs, da mesma forma que eles me dão força. Nossa resposta a essa violência deve ser ficando mais juntos, para nos ajudarmos, nos amarmos mais? (ARIANA GRANDE, 2017). 
É nesse sentido que respaldamos a proposta de Soares (2015) de que os artistas são peças centrais para um projeto de pacificação. 0 nosso trabalho, portanto, busca realizar uma avaliação desse tipo de projeto à luz desta análise de mecanismos dialógicos e linguístico-cognitivos. A tese é de que os artistas possuem certas qualidades que, dentro de uma estrutura de diálogo adequada (em que eles podem liderar contatos e chamar acordos, respaldados por organismos internacionais), podem servir a um resultado distinto do que vemos atualmente e temos visto ao longo de quase um século de relações diplomático-políticas.

Nossa justificativa é a de que tais agentes são ouvidos pelas partes envolvidas, têm habilidades comunicativas e mobilizadoras inigualáveis, conquistam reconhecimento em diferentes culturas, estão à margem da dependência de subgrupos de interesse econômico para manter sua agência operando, têm capacidade de liderança e angariam a atenção pública. No entanto, utilizar a agência dos artistas em uma estrutura diplomática como a atual não trará resultados promissores. Já testamos isso através da ONU, com seus embaixadores, sem resultado.

A proposta defendida é, assim, mudar a estrutura das relações diplomáticas (quem vai mediar, as instituições que lhes darão respaldo e a participação da mídia), empregando agentes que possam lograr sucesso na obtenção dos objetivos práticos requeridos. Tendo a etapa propositiva sido cumprida, passaremos para nossas considerações finais.

\section{Resultados e discussão}

Os resultados da pesquisa acerca do objeto empírico podem ser expressos enquanto considerações sobre a estrutura de negociação e sobre os agentes envolvidos. Destacamos, centralmente, os seguintes aspectos:

1. negociadores estiveram na linha de frente dos acordos entre as instituições e transmitiram informações para os reais tomadores de decisão, que estavam isolados do diálogo de barganha ali apresentado;

2. os membros dos grupos de negociação não tiveram o estatuto adequado para fechar os acordos: tomar as decisões e cumprir os acordos. Tais poderes encontram-se no âmbito da agência dos chefes dos Estados ${ }^{41}$;

3. relações de comprometimento dialógico ocorreram principalmente dentro de grupos e subgrupos. Os negociadores dependem de seus compromissos coletivos para manterem-se em suas funções, o que parece comprometer as negociações.

Ademais, podemos considerar que:

1. as posições no quadro das negociações são o resultado de compromissos coletivos

\footnotetext{
${ }^{41}$ É importante reiterarmos que a ANP não tem o mesmo estatuto político que o Estado de Israel, tanto no âmbito da ONU quanto de outras organizações internacionais. Muitos agentes políticos não reconhecem a Palestina enquanto Estado.
} 
firmados. Muitos, mesmo tomados como parte de negociação futura, são acordados anteriormente aos encontros oficiais, sendo apenas expressos nesses encontros;

2. existem relações de compromisso específicas para cada tipo de agente, restringindo os seus atos e dando-lhes razões para agir de uma determinada maneira. Como resultado, os compromissos com certas proposições variam de acordo com o nível de agência, com implicações para o processo de obtenção de paz. Mais uma vez, a decisão e o comprometimento estão ligados à agência, não ao indivíduo;

3. nesse sentido, propriedades de agência dialógica desempenham um papel na descrição de metas, intenções, submetas, ganhos, compromissos e posições de agentes e, como consequência, do significado comunicado;

4. diante de certos estímulos e do carisma manipulado por determinados agentes, é possível verificarmos uma conexão capaz de ultrapassar barreiras que outras formas de comunicação não conseguem, sobrepondo-se inclusive à agência social dos envolvidos (por exemplo, pessoas que têm interesses práticos divergentes). Tais agentes parecem conseguir colocar seu público em um estado emocional e representacional comum, tocando-lhes em sua individualidade e fazendo-os agir coletivamente. Os elementos de apelo, por hipótese universal, operariam sobre uma base que envolve nossos sentidos e representações. Como resultado, diante de estímulos desse tipo, podemos verificar alteração de nossos estados representacionais (intenções, metas, desejos etc.), emocionais e, consequentemente, de nossas tomadas de decisão.

Tais considerações podem ser confrontadas com dados da realidade, a fim de testarmos sua validade e o escopo de sua relevância ${ }^{42}$. Vale ressaltarmos que as relações diplomáticas entre os dois lados do conflito aqui abordado não apresentaram progresso considerável nos últimos anos.

\section{Conclusão}

Neste texto, contextualizamos a análise das negociações de paz israelo-palestinas. Como ponto central, apresentamos uma proposta alternativa de negociação mediada. Partimos da hipótese de uma estrutura dialógica partilhada pela espécie, aqui ilustrada através dos diálogos de paz, enquanto um tipo de diálogo de negociação ou barganha. Para além disso, descrevemos uma estrutura de agência que possibilita e regula os atos

\footnotetext{
42 A mais nova tentativa de aproximação entre as partes (grandes grupos institucionais) está sendo a intervenção direta do presidente norte-americano Donald Trump. Embora represente os compromissos conjuntos de seu país ou de grupos, que têm uma longa história de intervenção direta e indireta no conflito, ele possui a seu favor certo apelo carismático, prestígio enquanto negociador e isenção nas negociações prévias. Em termos de agência, ele faz parte do rol de líderes com amplo poder de voto e veto que têm, assim, condições de satisfazer comprometimentos diretamente firmados. Nos posicionamentos dos líderes envolvidos, vemos mescla de agência (The New York Times. Disponível em: <https://nyti.ms/2q8W3Lv>. Acesso em: 27 nov. 2017), mas não há nenhum tipo de acordo publicamente firmado, o que parece ser a meta do diálogo (? the ultimate deal国). 0 ponto é que a paz requerida significa um conjunto de mudanças no ambiente, que envolve questões objetivas (The New York Times. Disponível em: <https://nyti.ms/2q22dMw>. Acesso em: 27 nov. 2017).
} 
dos agentes envolvidos. De modo geral, exploramos a potencialidade representacional e expressiva das linguagens natural e não natural e de sua função social. Apontamos que são mecanismos linguísticos que possibilitam relações de compromisso, as quais, como as demais razões, motivam as ações dos agentes envolvidos.

Mais uma vez, conforme expresso em Dias (2016, p. 177-179), assumimos que uma base dialógica comum permite que nos comuniquemos, compartilhemos metas cognitivas e práticas e criemos metas coletivas. Buscamos, assim, descrever um cenário comunicativo em que a estrutura dialógica é a estrutura mais geral. Esse pressuposto nos permitiu fazer considerações sobre outros tipos de linguagem, enquanto meios de um contato dialógico eficaz, que podem ser levados para ambientes que requerem um contato mais efetivo entre as partes.

Quanto aos desacordos entre os representantes israelenses e palestinos, esses existem e têm sérias implicações em escala global. A região ainda não viu um acordo de paz, e todos os dias é atualizado o número das vítimas dessa situação. É difícil prevermos resultados diferentes obtidos pelos mesmos meios, isto é, por meio da mesma estrutura de negociação e das mesmas agências. Desse modo, justifica-se, novamente, nossa apresentação de um cenário alternativo de contato, alicerçado em um entendimento sobre o tipo de comunicação envolvida.

Buscamos, em nossa pesquisa (DIAS, 2016, p. 108-110, 180-190), dados para argumentar que nossas disposições cognitivas podem, sim, ser usadas em favor de melhores resultados. E isso requer mais do que mecanismos fisiológicos funcionando adequadamente, já que envolve padrões dialógicos e de agência. Os trechos aqui vistos são apenas uma fração do contínuo engajamento existente ${ }^{43}$. Novamente, a "negociação" representa um tipo de diálogo, do qual "conversas de paz", em contexto de conflito declarado, são um subtipo. Nesses processos de negociação, temos acomodação de objetivos, com vistas a acordos sob forma de atos de fala.

Em vista do mencionado, é compreensível questionarmos esse longo processo de negociação, que está longe de firmar e responder a um acordo efetivo. Como vimos, os representantes políticos falham em alcançar as condições mínimas para ter sucesso nessa tarefa. A ONU, do modo como se mostra em operação, também não consegue atingir os objetivos um dia propostos. Alternativas populares, por outro lado, baseiam-se, na sua maioria, em resistência armada. E a opinião pública não está ciente dos compromissos firmados e da agência envolvida (pontos que tentamos explorar em nosso trabalho), uma vez que o conhecimento desse conjunto de informações requer a compreensão de um contexto mais amplo, o que demanda esforços. Além disso, sabemos que o nível de

\footnotetext{
${ }^{43}$ Consideremos os movimentos apontados nas notícias publicadas pelo The Hill (disponível em: <https:// bit.ly/2zdVisP>. Acesso em: 27 nov. 2017) e pelo Haaretz (disponível em: <https://bit.ly/2tnf6EG>. Acesso em: 27 nov. 2017). Nesse contexto, destacamos o fato de que a mais bem-sucedida estratégia diplomática do governo Trump envolve o contato pela arte. Através de canções e poesia chinesa, a neta do presidente conquistou o respeito e a admiração dos povos envolvidos. Sobre o acontecimento, ver notícia do Estadão (disponível em: < https://bit.ly/2MCFlzJ>. Acesso em: 27 nov. 2017).
} 
complexidade da diplomacia atual é alto (leis, mapas, discursos públicos, atas, fóruns, reuniões, comitês etc.). É compreensível, assim, que o público esteja, em geral, distante dessa realidade. Esta é, na verdade, a evidência mais forte de que o processo de paz exige o envolvimento de outros agentes, que chamem atenção para etapas-chave, o que requer pessoas com potencial para sensibilizar agentes em direção a objetivos práticos comuns.

No atual cenário, o estado de paz requer mediadores célebres, como artistas e pessoas de apelo na grande mídia que, com seu carisma, conquistem os agentes envolvidos e os mobilizem para um acordo comum, a ser firmado e cumprido em um diálogo global.

\section{Referências bibliográficas}

ARIANA Grande fará show beneficente em Manchester para vítimas de atentado. G1, [S.l.], 26 maio 2017. Disponível em: <https://glo.bo/2lhf3GA>. Acesso em: 27 nov. 2017.

AUSTIN, John Langshaw. How to do things with words: the William James lectures. Oxford: Clarendon Press, 1962.

BARENBOIM, Daniel; SAID, Edward. Parallels and paradoxes: explorations in music and society. New York: Vintage Books, 2004.

CAPLAN, Neil. The Israel-Palestine conflict: contested histories. Malden, MA: WileyBlackwell, 2009.

CHOMSKY, Noam. New Horizons in the study of language and mind. Cambridge: Cambridge University Press, 2002.

COHEN, Laurence Jonathan. An essay on belief and acceptance. Oxford: Clarendon Press, 1992.

COSTA, Jorge Campos da. Diálogo. Questões interdisciplinares. In: FIGUEIREDO, Débora de Carvalho et al. (org.). Sociedade, cognição e linguagem - apresentações do IX CELSUL. 1. ed. Florianópolis: Insular, 2012. p. 149-169.

DIAS, Stéphane Rodrigues. A paz passa pelo discurso: a contribuição da linguística para a mediação de conflitos internacionais. In: ZANELLA, Cristine Koehler; DEITOS, Marc Antoni (org.). As relações internacionais em debate. 1. ed. Porto Alegre: UniRitter, 2013. v. 1. p. 87-97.

. ToM e o aparato comunicativo da linguagem. In: CONGRESO INTERNACIONAL DE LA ASOCIACIÓN DE LINGÜÍSTICA Y FILOLOGÍA DE AMÉRICA LATINA, 17., 2014, João Pessoa. Anais do XVII Congresso Internacional Associação de Linguística e Filologia da América Latina (ALFAL). João Pessoa: UFPB, 2014. v.1, p. 1124-1136.

. Agency via dialogue: a pragmatic, dialogue-based approach to agents. 2016. $202 \mathrm{f}$. Tese (Doutorado) - Faculdade de Letras, Pontifícia Universidade Católica do Rio Grande do Sul, Porto Alegre, 2016. Disponível em: <https://bit.ly/2JXpWeL>. Acesso em: 27 nov. 2017.

DIAS, Stéphane Rodrigues; MÜLLER, Felipe de Matos. Speaker or agent? Implications and applications. In: PEREIRA, Vera Wannmacher et al. (orgs.). Gate to pragmatics: uma 
introdução a abordagens, conceitos e teorias da pragmática. Porto Alegre: EDIPUCRS, 2017. Recurso eletrônico.

EISENBERG, Laura Zittrain; CAPLAN, Neil. Negotiating Arab-Israeli peace: patterns, problems, possibilities. Bloomington: Indiana University Press, 2010.

FREGE, Gottlob. Sobre o sentido e a referência. In: ALCOFORADO, Paulo (org. e trad.). Lógica e filosofia da linguagem. São Paulo: Cultrix; São Paulo: Edusp, 1978. p. 61-86).

GELVIN, James L. The Israel-Palestine conflict: one hundred years of war. 3. ed. Los Angeles: University of California, 2014.

GILBERT, Margaret. Modelling collective belief. Synthese, Dordrecht, v. 73, n. 1, p. 185-204, 1987.

Sociality and responsibility: new essays in plural subject theory. London: Rowman and Littlefield, 2000.

GRICE, H. Paul. Studies in the way of words. Cambridge, MA: Harvard University Press, 1989.

HYMES, Dell. On communicative competence. In: PRIDE, J. B.; HOLMES, Janet (eds.). Sociolinguistics. Selected Readings. Hardmonsworth: Penguin, 1972. p. 269-293.

JUNG, Nadine et al. How emotions affect logical reasoning: evidence from experiments with mood-manipulated participants, spider phobics, and people with exam anxiety. Frontiers in Psychology, Lausanne, v. 5, p. 1-12, 2014. Artigo 570.

KEINON, Herb. US to allow PLO office to remain open with 'limitations'. The Jerusalem Post, Jerusalem, 26 nov. 2017. Disponível em: <https://bit.ly/2tcELzI>. Acesso em: 17 nov. 2017.

LEPORE, Ernest; STONE, Matt. Imagination and convention: distinguishing grammar and inference in language. Oxford: Oxford University Press, 2015. 292 p.

LERNER, Jennifer. S. et al. Emotion and decision making: online supplement. Annual Review of Psychology, Palo Alto, v. 66, p. 33.1-33.25, 2015. Disponível em: <https://bit. ly/2ybZY2A>. Acesso em: 30 nov. 2017.

LEVINSON, Stephen C. Presumptive meanings: the theory of generalized conversational implicature. Cambridge, MA: MIT Press, 2000.

LIST, Christian; PETTIT, Phillip. Group agency: the possibility, design, and status of corporate agents. Oxford: Oxford University Press, 2011.

MACAGNO, Fabrizio; BIGI, Sarah. Analyzing the pragmatic structure of dialogues. Discourse Studies, Thousand Oaks, v. 19, n. 2, p. 148-168, 2017.

MACAGNO, Fabrizio; WALTON, Douglas. Implicatures as forms of argument. In: CAPONE, Alessandro et al. (eds.). Perspectives on pragmatics and philosophy. New York: Springer, 2014. p. 203-224.

MERCIER, Hugo; SPERBER, Dan. The enigma of reason: a new theory of human understanding. Harvard: Harvard University Press, 2017.

Why do humans reason? Arguments for an argumentative theory. Behavioral and brain sciences, Cambridge, v. 34, n. 2, p. 57-111, 2011.

ORIGGI, Gloria; SPERBER, Dan. Evolution, communication and the proper function of 
language. In: CARRUTHERS, Peter; CHAMBERLAIN, Andrew (eds.). Evolution and the human mind: language, modularity and social cognition. Cambridge: Cambridge University Press, 2000. p. 140-169

PALESTINE Liberation Organization. Permanent Observer Mission of the State of Palestine to the United Nations, New York, 1 Feb. 2001. Disponível em: <https://bit.ly/2JHsQoD>. Acesso em: 27 nov. 2017.

PINKER, Steven. The language instinct. New York: Harper Perennial Modern Classics, 1994.

SCHMITT, Fredrick. The justification of group beliefs. In: ___ (org.). Socializing epistemology: The social dimensions of knowledge. Lanham: Rowman and Littlefield, 1994. p. 257-287.

SEARLE, John R. A taxonomy of illocutionary acts. In: GÜNDERSON, Keith (ed.). Language, mind and knowledge. Minneapolis: University of Minnesota Press, 1975. v. 7. p. 344-369.

. The construction of social reality. New York: The Free Press; Harmondsworth, Middlesex: Penguin Books, 1995.

. Meaning, mind and reality. Revue Internationale de Philosophie, Bruxelles, v. 2, n. 216, p. 173-179, 2001.

. Making the social world: the structure of human civilization. Oxford: Oxford University Press, 2010.

; VANDERVEKEN, Daniel. Foundations of Illocutionary Logic. Cambridge: Cambridge University Press, 1985.

SOARES, Paulo. 1980-1996, Letters between Michael Jackson and João Paulo II. Porto Alegre: Edição do autor, 2015.

SPERBER, Dan. Understanding verbal understanding. In: KHALFA, Jean (ed.) What is intelligence? Cambridge: Cambridge University Press, 1994. p. 179-198.

. How do we communicate? In: BROCKMAN, John; MATSON, Katinka (eds). How things are: a science toolkit for the mind. New York: Morrow, 1995. p. 191-199.

SPERBER, Dan; WILSON, Deirdre. Relevance: communication and cognition. Cambridge: MIT Press, 1986.

Press, 1995.

THE PALESTINE PAPERS. Meeting minutes: Saeb Erekat and Dov Weisglass. Al Jazeera Investigations, Doha, 3 Feb. 2005. Disponível em: <https://bit.ly/2JX8GpU>. Acesso em: 27 nov. 2017.

. Meeting minutes: Saeb Erekat and Dov Weisglass. Al Jazeera Investigations, Doha, 14 Feb. 2005. Disponível em: <https://bit.ly/2JX8GpU>. Acesso em: 27 nov. 2017.

TIERSMA, Peter Meijes. The language of offer and acceptance: speech acts and the question of intent. California Law Review, Berkeley, v. 74, n. 1, p. 189-232, 1986.

TOMASELLO, Michael. Constructing a language: a usage-based theory of language acquisition. Cambridge: Harvard University Press, 2003.

. Origins of human communication. Cambridge: MIT Press, 2008.

TOMASELLO, Michael; RAKOCZY, Hannes. What makes human cognition unique? From 
individual to shared to collective intentionality. Mind \& Language, Hoboken, v. 18, n. 2, p. 121-147, 2003.

UNITED NATIONS. The plan of partition and end of the British mandate. In:

Department of Public Information. The question of Palestine \& the United Nations. New York: United Nations, 2003. Disponível em: <https://bit.ly/2p6Zkhy>. Acesso em: 17 nov. 2017.

WALTON, Douglas N. Informal logic. Cambridge: Cambridge University Press; Albany: State University of New York Press, 1989. 2007.

Dialog theory for critical argumentation. Amsterdam: John Benjamins Publishers,

POWELL, Lindsey. J.; SPELKE, Elizabeth. S. Preverbal infants expect members of social groups to act alike. Proceedings of the National Academy of Sciences, Washington, DC, v. 110, n. 41, p. E3965-E3972, 2013.

WALTON, Douglas N.; KRABBE, Erik C. W. Commitment in dialogue: basic concepts of interpersonal reasoning. Albany: State University of New York Press, 1995.

WEIGAND, Edda. Language as dialogue: from rules to principles of probability. Philadelphia: John Benjamins, 2009.

Dialogue: the mixed game. Philadelphia: John Benjamins, 2010.

WILSON, Deirdre. New directions for research on pragmatics and modularity, Lingua, Amsterdam, v. 115, n. 8, p. 1129-1146, 2005.

YEUNG, Ruth M. W. et al. Emotion and revisit intention: true across all emotion-based segments? In: CAUTHE Conference, 24., 2014, Brisbane. Proceedings... Brisbane: School of Tourism, The University of Queensland, 2014. Disponível em: <https://bit.ly/2Mvbadr>. Acesso em: 30 nov. 2017.

Texto recebido em: 21 de Abril de 2018 Aprovado para publicação em: 19 de Dezembro de 2016 